\title{
Resonant Laser Ablation as a Selective Metal Ion Source for Gas-Phase Ion Molecule Reactions
}

\author{
C. G. Gill, A. W. Garrett, P. H. Hemberger, and N. S. Nogar \\ Chemical Science and Technology Division, MS J565, Los Alamos National Laboratory, Los Alamos, New \\ Mexico, USA
}

\begin{abstract}
Resonant laser ablation (RLA) is used as a source to selectively generate multiple metal ion species from the same sample. The capability of rapidly changing metal ions for gas-phase ion chemistry studies is a significant advantage in ion-molecule chemistry. The simple experimental arrangement uses relatively modest laser pulse energies ( $\leq 25 \mu \mathrm{J} /$ pulse) from a tunable dye laser to desorb and selectively ionize different metal atoms from a multicomponent sample. In turn, this allows the chemistry of several components to be investigated without breaking vacuum or altering the experimental geometry. This work demonstrates the use of RLA as a selective source of several reagent metal ions for gas-phase ion chemistry investigations. In particular, the reactivity of acetone with $\mathrm{Cr}^{+}, \mathrm{Fe}^{+}, \mathrm{Ni}^{+}$, and $\mathrm{Cu}^{+}$was examined for metal ions selectively created by RLA from a standard steel sample. ( $/ \mathrm{Am} \mathrm{Soc}$ Mass Spectrom 1996, 7, 664-667)
\end{abstract}

$\mathrm{M}$ ass spectrometric investigations of the gasphase chemistry of metal ions have been conducted since the early 1970s. Early studies [1-8] involved the use of thermionic emitters for metal ion production and mass spectrometers for reaction and product analysis. Subsequent investigations led to the exploitation of alkali and transition metal ions as chemical ionization $(\mathrm{Cl})$ reagents for aliphatic molecules. Many comprehensive reviews of gas-phase metal ion chemistry [9-14] are available.

Most gas-phase ion chemistry studies now use ion storage-type mass spectrometers (i.e., Fourier transform ion cyclotron resonance, quadrupole ion traps) as "gas-phase test tubes." The use of quadrupole ion trap mass spectrometers (ITMS) for metal ion chemistry studies can be traced back to Cooks and co-workers [15], who used a simple laser desorption experiment to examine the ion chemistry of gold ions with benzene. Recent quadrupole ion trap research used laser ablation to create metal ions for comprehensive studies [ 16 , 17] of gas-phase complexation of metal ions with organic ligands. In addition to laser generation, a variety of sources have been used for metal ion production. Alkali metals are readily generated via thermionic emission sources [1-8, 18]. In addition, some metal ions can be produced by electron impact of their corresponding metal carbonyls [19].

Address reprint requrest to N. S. Nogar, CST-1, J565, Los Alamos National Laboratory, Los Alamos, New Mexico 87545.
An alternate mode for creation of gas-phase metal ions is through laser ablation of pure metal and mixed metal samples [20] directly within the storage cell of the mass spectrometer. Here, we define ablation as the direct generation of gas-phase ions that result from the laser-material interaction. Previous work with pure metal ion sources required that the metal source be changed; this often involves the temporary corruption of the high vacuum environment and leads to modified, although similar, conditions after the change. Selective metal ion production by ablation of several metal targets mounted in an FT-ICR cell [21] has been successfully implemented by adjusting the focus of the laser. This method works for FT-ICR applications, but is cumbersome due to sample size considerations when applied to quadrupole ion trap mass spectrometers.

Research in this laboratory has been directed at using resonant laser ablation (RLA) [22-24] as a means of selectively creating different types of metal ions from a multicomponent sample. In the work described here, all reagent metal ions investigated were created selectively from the same sample by simply tuning the dye laser ( $\leq 24 \mu \mathrm{J} /$ pulse) to the appropriate " $2+1$ " (photons to resonance + photons to ionize) transition. This method is simple to implement and may eventually allow the use of resonant excitation processes to selectively generate excited state ions, through the use of autoionizing resonances, to explore the chemistry of these excited states. For a test system, we choose the reaction of several first-row transition elements $\mathrm{CCr}^{+}$, $\mathrm{Fe}^{+}, \mathrm{Ni}^{+}$, and $\left.\mathrm{Cu}^{+}\right)$with acetone. This reaction system 
(and similar reactions with other aldehydes and ketones) has been studied previously [21, 25] and serves as a convenient benchmark.

\section{Experimental}

The ion trap used for these experiments has been described in detail elsewhere [26, 27] and is only summarized here. A Finnigan-MAT (San Jose, CA) ITMS electrode assembly is mounted inside a 1-m-diameter vaccuum manifold capable of base pressures $\leq 10^{-8}$ torr. A XeCl excimer laser $(308 \mathrm{~nm}, 15 \mathrm{~ns}, 80$ $\mathrm{mJ} /$ pulse) was used to pump a dye laser $(400-500 \mathrm{~nm}$, $\leq 5 \mathrm{~mJ} /$ pulse, $\approx 0.2-\mathrm{cm}^{-1}$ bandwidth, 12-ns pulse). The pulse energy of the dye laser was controlled precisely by a variable attenuator (NRC, Fountain Valley, $N Y$, 935-5). typical laser pulse energies were $\leq 25 \mu \mathrm{J}$, with the laser fluence at the desorption site $\leq 320$ $\mathrm{mJ} / \mathrm{cm}^{2}$, which corresponds to an intensity of $\leq 27$ $\mathrm{MW} / \mathrm{cm}^{2}$. Laser pulse energy was monitored directly by insertion of a power meter (Laser Precision, Utica, NY, RJ7620/R5P735) in the beam line. The laser pulse energy that reaches the sample is $\sim 15 \%$ less intense than the quoted values due to losses at the final folding mirror, vacuum window, and focusing lens.

The National Institute of Standards and Technology (NIST) sample (C1288) used to generate metal ions was machined into a probe tip that was inserted through a hole in the ring electrode of the ion trap so that its tip was flush with the electrode's inner surface. Prior to use, the probe was cleaned with successive washes by using nitric acid, deionized water, methanol, and acetone, and then air dried. The laser beam was propagated through a hole in the opposite side of the ring electrode and focused onto the probe tip at normal incidence.

Acetone (J. T. Baker, Phillipsburg, NJ, ACS grade, 99.7\%) used for gas-phase ion molecule studies was subjected to several freeze-pump-thaw cycles, and then leaked into the vacuum manifold at an uncorrected pressure of $4.0 \times 10^{-7}$ torr. Special purity helium (U.S. Department of Interior/Bureau of Mines, Amarillo, TX; <1-ppm impurities) was used as a buffer gas at an uncorrected gauge pressure of $3.0 \times$ $10^{-5}$ torr.

Metal ions were created within the storage volume of the ion trap by RLA and allowed to react with acetone for a $50-\mathrm{ms}$ period. Ions were trapped at a $35-\mathrm{u}$ low-mass cutoff, which corresponds to $q_{z}\left({ }^{52} \mathrm{Cr}\right)=$ $0.61, q_{z}\left({ }^{56} \mathrm{Fe}\right)=0.57, q_{z}\left({ }^{58} \mathrm{Ni}\right)=0.55$, and $q_{z}\left({ }^{65} \mathrm{Cu}\right)=$ 0.49 . The products were analyzed by a mass scan of the ion trap. The method of "dynamic" rf trapping" [27, 28] was employed to increase the trapping efficiency for the laser-generated metal ions. Thirty scans were averaged for each spectrum.

\section{Results and Discussion}

The intent of this work was to demonstrate the usefulness of RLA for selective metal ion generation as applied to gas-phase ion chemistry investigations. To selectively ionize different metal ions from the same sample, $2+1$ (photons to resonance + photons to ionize) ionization schemes are employed. Table 1 lists the transitions used to ionize various metals from NIST sample C1288. A more comprehensive compilation of other $2+1$ resonant transitions is given elsewhere [29]. To verify that the ionization process is indeed resonant in nature, optical resonance scans were conducted for each transition, in which the desired ion signal is plotted versus photon energy (or wavelength). Figure 1 shows the optical spectrum for the $\mathrm{Ni}(2+1)$ transitions at $471.7 \mathrm{~nm}$, and Table 1 lists the transitions responsible for the two resonances observed. The laser pulse energy used for this scan was $25 \mu \mathrm{J}$. No mass spectral peaks were observed for $\mathrm{Ni}$ or any other component of the sample when the laser was off resonance; this illustrates the selective nature of RLA as an ionization method. In other work [22, 29], we have demonstrated ionization selectivity of the target analyte versus the bulk material of $\geq 10^{5}: 1$.

By using the transitions listed in Table 1, different reagent metal ions were selectively created from the same sample. The chosen metal ions were stored in the ion trap and allowed to react for $50 \mathrm{~ms}$ with gas-phase acetone. Mass spectra were then obtained to determine

Table 1. Summary of excitation and reactives for resonant laser ablation ${ }^{a}$

\begin{tabular}{ccccccccc}
\hline & $\begin{array}{c}\text { Concentration } \\
\text { in SRM } \\
\text { C1288 }\end{array}$ & $\begin{array}{c}\text { Ground } \\
\text { state }\end{array}$ & $\begin{array}{c}\text { Excited } \\
\text { state }\end{array}$ & $\begin{array}{c}\text { Energy } \\
\left(\mathrm{cm}^{-1}\right)\end{array}$ & $\begin{array}{c}\text { lon ground } \\
\text { state }\end{array}$ & $\begin{array}{c}\text { lonization } \\
\text { potential } \\
(\mathrm{cm}-1)\end{array}$ & $\begin{array}{c}2+1^{\prime \prime} \\
\lambda \\
(\mathrm{nm})\end{array}$ & $\begin{array}{c}\text { Reaction } \\
(\%)\end{array}$ \\
\hline \hline $\mathrm{Cr}$ & 19.55 & $\left(3 d^{5} 4 s\right) a^{7} S_{3}$ & $\left(3 d^{5} 4 d\right) e^{7} D_{3}$ & 42256.3 & $\left(3 d^{5}\right)^{6} S_{5 / 2}$ & 54576.6 & 473.17 & 18 \\
$\mathrm{Fe}$ & 42.68 & $\left(3 d^{6} 4 s^{2}\right) a^{5} D_{4}$ & $\left(3 d^{6} 4 s 5 s\right) e^{5} D_{4}$ & 44677.0 & $\left(3 d^{6} 4 s\right)^{6} D_{9 / 2}$ & 63737 & 447.5 & 60 \\
$\mathrm{Cu}$ & 3.72 & $\left(3 d^{10} 4 s\right)^{2} S_{1 / 2}$ & $\left(3 d^{10} 5 s\right)^{2} S_{1 / 2}$ & 43137.2 & $\left(3 d^{10}\right){ }^{1} S_{0}$ & 62317.2 & 463.51 & 73 \\
$\mathrm{Ni}$ & 29.3 & $\left(3 d^{9} 4 s\right) a^{3} D_{3}$ & $\left(3 d^{9} 5 s\right) e^{3} D_{3}$ & 42606.0 & $\left(3 d^{9}\right) e^{2} D_{5 / 2}$ & 61600 & 471.69 & 86 \\
& & $\left(3 d^{9} 4 s\right) a^{3} D_{1}$ & $\left(3 d^{9} 5 s\right) e^{3} D_{1}$ & 44112.2 & $\left(3 d^{9}\right) e^{2} D_{5 / 2}$ & 61600 & 471.71 & 86 \\
\hline
\end{tabular}

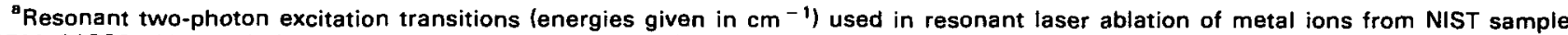
SRM C1288. Also included is the composition of $\mathrm{C} 1288$ for the metals used by this study, the percent reactions, and the ionization potentials. All transitions listed originate in the lowest energy spin-orbit level of the ground state term $\left(0 \mathrm{~cm}^{-1}\right)$ except for those of Ni which start from $204.4 \mathrm{~cm}^{-1}$ for $\left(3 d^{9} 4 s\right) a^{3} D_{3}$ and $1713.1 \mathrm{~cm}^{-1}$ for $\left(3 d^{9} 4 s\right) a^{3} D_{1}$.
} 
the nature of the products for the reaction of $\mathrm{Cr}^{+}, \mathrm{Fe}^{+}, \mathrm{Ni}^{+}$, or $\mathrm{Cu}^{+}$with acetone in the gas phase. The net reactions (not mechanisms) for the various metal ions $\left[\mathrm{M}^{+}\right]$with acetone is adduct or bi-adduct formation:

$$
\begin{gathered}
\mathrm{M}^{+}(\mathrm{g})+\left(\mathrm{CH}_{3}\right)_{2} \mathrm{CO}(\mathrm{g}) \rightarrow \mathrm{M}\left(\mathrm{CH}_{3}\right)_{2} \mathrm{CO}^{+}(\mathrm{g}) \\
\mathrm{M}\left(\mathrm{CH}_{3}\right)_{2} \mathrm{CO}^{+}(\mathrm{g})+\left(\mathrm{CH}_{3}\right)_{2} \mathrm{CO}(\mathrm{g}) \\
\rightarrow \mathrm{M}\left\{\left(\mathrm{CH}_{3}\right)_{2} \mathrm{CO}_{2}^{+}(\mathrm{g})\right.
\end{gathered}
$$

Product mass spectra for this reaction with copper (the least abundant of our reagent elements) and iron (bulk metal component) are given in Figure 2. The ion adducts shown in the figure exhibit the characteristic isotopic distribution for the reagent metal ions used, which confirms that the observed products are metal-organic adduct products. For iron and nickel ions (nickel not shown), $\mathrm{M}\left(\mathrm{H}_{2} \mathrm{O}\right)^{+}$and $\mathrm{M}(\mathrm{CO})^{+}$also were observed as reaction products.

Our results can be compared with previous reports of metal-ion reactivities with acetone $[10,21,25,30$, 31]. Iron was initially reported [21] to insert into one of the carbon-carbon bonds, followed by elimination of either $\mathrm{CO}$ or (predominately) $\mathrm{C}_{2} \mathrm{H}_{6}$ to produce the corresponding product ions $\mathrm{Fe}\left(\mathrm{CH}_{3}\right)_{2}^{+}$or $\mathrm{FeCO}^{+}$. It later was found [31] that $\mathrm{FeCO}^{+}$could react further with acetone to produce the adduct and bi-adduct products. The latter work also reported some evidence that the adduct could be formed directly by stabilization of the addition product. Nickel was found to undergo dissociative attachment reactions similar to those exhibited by iron $[10,30]$. No mention was made of the formation of the adduct or bi-adduct ions. Copper initially was reported [25] to undergo no dissociative attachment reactions with acetone, whereas later work did report the production of the direct condensation (adduct) product [31]. We found no previous

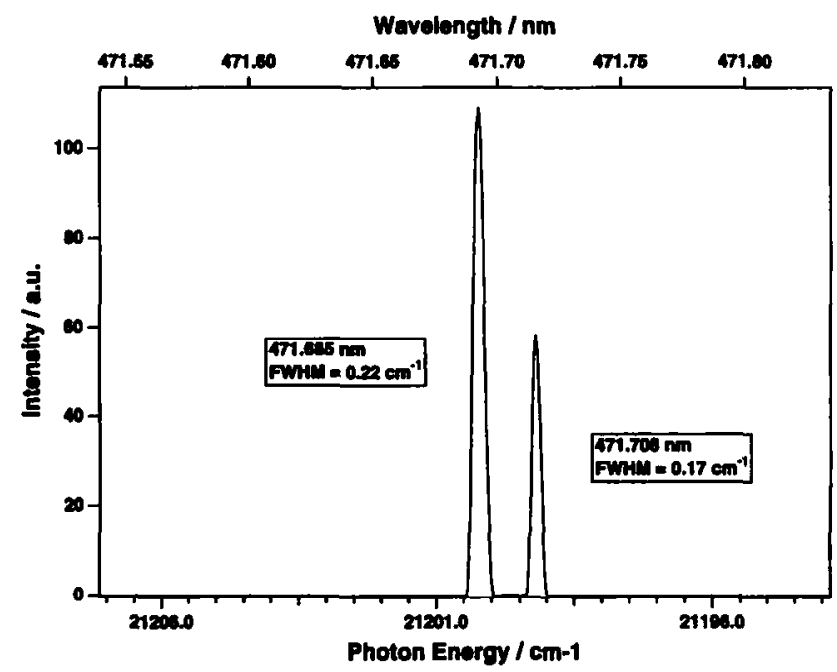

Figure 1. The optical $2+1$ spectrum for nickel used for these experiments. The measured linewidths are limited by the bandwidth of the dye laser $\left(0.2 \mathrm{~cm}^{-1}\right)$. The corresponding transitions are given in Table 1.

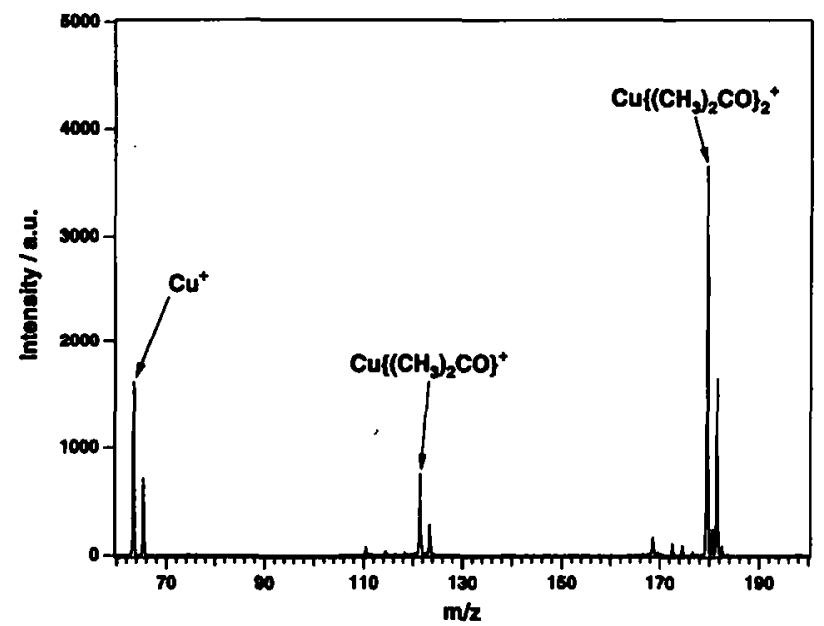

(a)

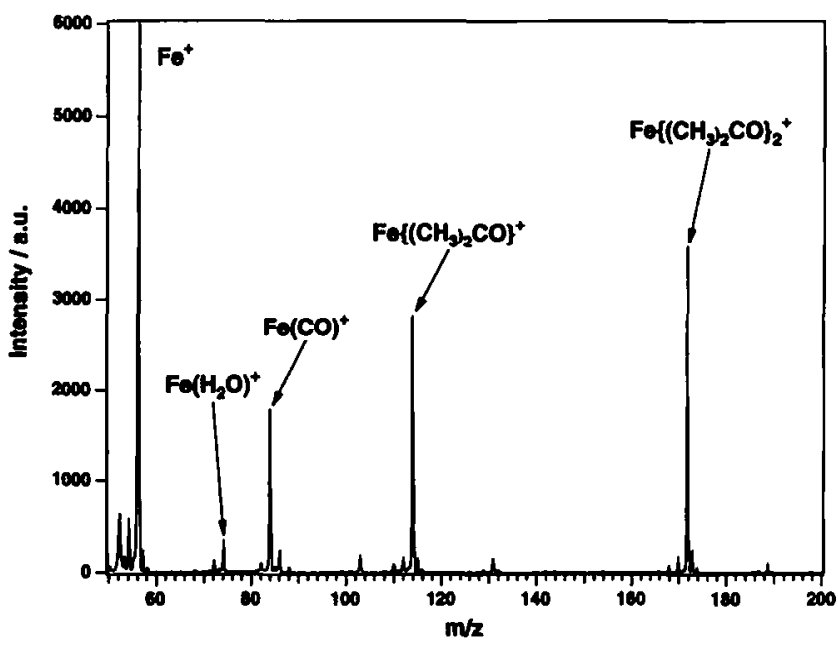

(b)

Figure 2. Product ion mass spectra for gas-phase metal ion + acetone adducts that result from the RLA selective ionization of (a) copper and (b) iron from NIST C1288 steel. The metal sample composition is given in Table 1 , along with the $2+1$ resonance transitions used. The unassigned minor peaks observed in each mass spectrum are attributed to minor nonresonantly ionized species generated during the ablation process and their subsequent reaction products.

reports on the reaction of chromium ions with acetone or other ketones.

Our experiments show that the metal ions examined form single and bi-adduct ions, with some evidence of dissociative attachment reactions for both $\mathrm{Fe}^{+}$ and $\mathrm{Ni}^{+}$metal ions (the metal carbonyl ions were observed). The similarity between previously published studies and the results of this work suggest that the RLA metal ion source is a viable method for metal ion chemistry investigations. Additionally, RLA coupled with quadrupole ion trap mass spectrometry for ion chemistry investigations is a favorable pairing of technologies for several reasons. First, space-charge effects are reduced; selective production of metal ions results in far fewer total number of ions being produced than with nonselective ablation of a multicom- 
ponent target. Second, when RLA is used, metal ions are produced by relatively low intensity laser irradiation (compared to the conditions used in most of the ion cyclotron resonance experiments), which results in a rather low energy distribution for the resultant ions [32]. In addition, the reagent ions are further cooled translationally by collisions at the relatively high pressures ( $\leq 10^{-5}$ torr) used in the ITMS experiments, although electronic cooling with $\mathrm{He}$ is unlikely at these pressures [33]. Third, the pressures used in ITMS are more likely to collisionally stabilize the adducts, so that relatively fragile products can be observed, which thereby increases the utility of this technique for $\mathrm{Cl}$ studies. Metal ion $\mathrm{Cl}$ research is currently under examination in this laboratory as an alternative strategy for the analysis of molecules that undergo extensive El fragmentation.

The reactivity of the various metal ions studied is presented in Table 1 . The only difference between each type of metal ion chemistry examined (aside from the differing metal reagent ions) was the color of the laser light used to selectively create the required metal reagent ions. All experiments were conducted at the same partial pressure of acetone, and the metal ions were created selectively from the same sample. Thus, the vacuum environment was virtually identical for each experiment. All reagent metal ions examined by this study were fourth row transition metals ( $3 d$ orbital configuration), with electron configurations as indicated in Table 1. The observed gas-phase reactivity of these metal ions with acetone molecules approximately scales with the first ionization potential (IIP) for the metal atoms, as has been suggested previously [8]. This trend is illustrated in Table 1, which shows the percent reaction and the first ionization potential (IP) for the various metal ions. Percent reaction is expressed as

\section{$\{(\Sigma$ product ion signals $) /(\Sigma$ total ion signals $)\} \times 100$}

The results show an increase in percent reaction as the ionization potential of the specific metal reagent ion increases.

We have demonstrated the utility of selected metal ion generation from a multiple component target for the study of reaction trends in gas-phase ion-molecule reactions. Metal ions are generated by a process that involves laser ablation and selective ionization that is termed resonant laser ablation [22-24]. This process produces relatively low energy metal ions with a high degree of selectivity and has the potential for selective production of ionic excited states through the use of autoionizing resonances. The reactivity of the ions was found to scale roughly with the ionization potential of the metal, which probably reflects electrophilic attack on the $\pi$-bonding [34] or oxygen nonbonding electrons.

\section{References}

1 Dzidic, I.; Kebarle, P. J. Phys. Chem. 1970, 74, 1466-1474.

2 Kabarle, P. In Higher-Order Reactions, Ion Clusters and Ion Solvation; Franklin, J. L., Ed.; Plenum: New York, 1972; Pp 315-362.

3 Rode, B. M. Chem. Phys. Lett. 1975, 35, 517-520.

4 Woodin, R. L.; Beauchamp, J. L. J. Am. Chem. Soc. 1978, 100, 501-508.

5 Hodges, R. B.; Beauchamp, J. L. Anal. Chem. 1976, 48 825-829.

6 Davidson, W. R.; Kebarle, P. J. Am. Chem. Soc. 1976, 98, 6125-6133.

7 Castleman, A. W., Jr. Chem. Phys. Lett. 1978, 53, 560-564.

8 Allision, J.; Ridge, D. P. J. Am. Chem. Soc. 1979, 101, 4998-5009.

9 Good, A. Chem. Rev. 1975, 75, 561-583.

10 Freiser, B. S. Anal. Chim. Acta. 1985, 178, 137-158.

11 Allison, J. Prog. Inorg. Chem. 1986, 34, 627-676.

12 Vairamani, M, Mirza, U. A.; Srinivas, R. Mass Spectrom. Rev. 1990, 9, 235-258.

13 Teesch, L. M.; Adams, J. Org. Mass Spectrom. 1992, 27, 931-943.

14 Teesch, L. M.; Adams, J. In Gas Phase Chemistry of Alkali Adducts of Simple and Complex Molecules Russel, D. H., Ed.; Plenum: New York, 1994; pp 39-68.

15 Louris, J. N.; Brodbelt-Lustig, J. S.; Kaiser, R. E.; Cooks, R. G. Proceedings of the 36th ASMS Conference on Mass Spectrometry and Allied Topics; San Diego, CA, 1985; p 968.

$16 \mathrm{Wu}$, H. F.; Brodbelt, J. S. J. Am. Chem. Soc. 1994, 116, 6418.

$17 \mathrm{Wu}, \mathrm{H}$. F.; Brodbelt, J. S. J. Incl. Phenom. Molec. Recog. Chem. 1994, 18, 37.

18 Wieting, R. D.; Staley, R. H.; Beauchamp, J. L. I. Am. Chem. Soc. 1975, 97, 924-926.

19 Peake, D. A.; Gross, M. L. Anal. Chem. 1985, 57, 115-120.

20 Cody, R. B.; Burnier, R. C.; Reents, W. D., Jr.; Carlin, T. J.; McCrery, D. A.; Lengel, R. K.; Freiser, B. S. Int. J. Mass Spectrom. Ion Phys. 1980, 33, 37-43.

21 Burnier, R. C.; Byrd, G. D.; Freiser, B. S. J. Am. Chem. Soc. 1981, 103, 4360-4367.

22 Eiden, G. C.; Anderson, J. E.; Nogar, N. S. Microchem. J. 1994, 50, 289-300.

23 Eiden, G. C.; Nogar, N. S. Chem. Phys. Lett. 1994, 226, 509-516.

24 Allen, T. M.; Kelly, P. B.; Anderson, J. E.; Taylor, T. N.; Nogar, N. S. Appl. Phys. A: Mater. Sci. Process. 1995, A61, 221-225.

25 Burnier, R. C.; Byrd, G. D.; Freiser, B. S. Anal. Chem. 1980, 52, 1641-1650.

26 Alexander, M. L.; Hemberger, P. H.; Cisper, M. E.; Nogar, N. S. Anal. Chem. 1993, 65, 1609-1614.

27 Eiden, G. C.; Garrett, A. W.; Cisper M. E.; Nogar, N. S.; Hemberger, P. H. Int. J. Mass Spectrom. Ion Processes 1994, $136,119-141$.

28 Eiden, G. C.; Cisper, M. E.; Alexander, M. L.; Hemberger, P. H.; Nogar, N. S. J. Am. Soc. Mass Spectrom. 1993, 4, 706-709.

29 Gill, C. G.; Garrett, A. W.; Hemberger, P. H.; Nogar, N. S. Spectrochimica Acta 1996, in press.

30 Freiser, B. S. Talanta 1985, 32, 697-708.

31 Surjasasmita, P. I.; Freiser, B. S. I. Am. Soc. Mass Spectrom. 1993, 4, 135-144.

32 Gill, C. G.; Allen, T. M.; Anderson, J. E.; Taylor, T. N.; Kelly, P. B.; Nogar, N. S. Appl. Opt. 1996, in press.

33 Levine, R. D.; Bernstein, R. B. Molecular Reaction Dynamics; Oxford University Press: New York, 1974; Chap. 5.

34 Dougherty, D. A. Science 1996, 271, 163-168. 